\title{
A reexamination on how behavioral interventions can promote household action to limit climate change
}

\author{
Paul C. Stern ${ }^{1 \times}$ \\ ARISING From Claudia F. Nisa et al. Nature Communications https://doi.org/10.1038/s41467-019-12457-2
}

T here has been a long-standing debate on whether and how behavioral interventions can reduce the contribution of household actions to climate change. Nisa et al. ${ }^{1}$ review randomized field trials and find that behavioral interventions, taken alone, have very little effect on household actions. Although many readers might inappropriately conclude that such interventions have no meaningful place in efforts to limit climate change, a long-standing body of multimethod research shows that when combined with non-behavioral interventions to address context-specific barriers to change, behavioral interventions can greatly increase the impact of household actions. Further research should focus on high-impact actions, use multiple research methods, and combine different types of interventions to explore how and under what conditions behavioral interventions can have practical value.

Behavioral interventions are roughly defined in the literature to include interventions that involve neither command-andcontrol regulations nor financial incentives-e.g., information provision, appeals to values and norms, engagement, and restructuring choice options (so-called nudges). Despite the strong analysis in ref. ${ }^{1}$, an inference of no practical value is inappropriate for three main reasons. First, the analysis covers only behavioral interventions acting alone. However, as elaborated below, long-standing literature indicates that the most effective ways to use behavioral interventions to change household actions affecting GHG emissions are not alone, but in combination with financial and other interventions $s^{2-4}$. The findings in ref. ${ }^{1}$ will not surprise readers familiar with that literature. But it contributes by showing through careful methodological analysis that behavioral interventions on their own have small average effects on the household behaviors studied, even when the effects are statistically significant. These findings may help stimulate behavioral researchers to rethink how best to use behavioral interventions for real-world impact.

Second, the paper does not distinguish clearly between frequently occurring behaviors (e.g., travel to work, adjusting room temperatures, changing diet), whose effects must be aggregated through multiple repetitions, and infrequent behaviors, usually involving investments, whose effects are almost fully achieved by a single action (e.g., upgrading the energy efficiency of building shells, adopting more energy-efficient home power systems and vehicles). All but four of the randomized controlled trials reviewed examine the first class of behaviors (the others concern appliance choices), but the authors do not fully consider the implications of that fact. The paper barely addresses the household behaviors with the greatest potential for reducing GHG emissions on a time scale of years to decades, which are of the single-action type ${ }^{3}$. These actions include home weatherization and acquisition of fuel-efficient vehicles, which both have a far greater technical potential for emissions reduction than appliance purchases ${ }^{3}$. Other one-time actions that have become more widespread in recent years, such as adoption of photovoltaic energy systems and electric vehicles that can run on them, arguably also have much greater potential importance than appliance purchases or frequently occurring behaviors. There has long been evidence that the determinants for the two types of action are different and that intrapersonal factors have less effect on investments ${ }^{5}$. Because this paper barely addresses such highimpact behaviors, the practical relevance of the meta-analysis is open to question. For example, the problem of establishing habits, discussed in ref. ${ }^{1}$ as whether the behaviors stand the test of time, has an important place in that paper, but seems irrelevant for one-time behaviors.

The meta-analysis sample reflects the history of behavioral researchers' focus on frequently repeated behaviors ${ }^{4,6}$ and may reflect the difficulty of organizing randomized control studies of higher-impact one-time household investments. This gap in the literature is important: a focus on potentially high-impact behaviors is critical for behavioral research to make its greatest contribution, especially as the determinants of the two kinds of behavior may well be different ${ }^{4,5}$. Research on high-impact behaviors uses various non-experimental methods, is limited and fragmentary, but yet suggests some conclusions of practical value ${ }^{4,7-9}$. Because a review restricted to randomized clinical trials omits the highest-impact 
household actions, its conclusions need to be qualified carefully before drawing general inferences about the potential impact of behavioral interventions. A focus on high-impact actions points to the great importance of context-specific barriers to change and the value of combining behavioral with regulatory and financial interventions.

Third, the paper acknowledges, but is unable to explore, the potential for behavioral interventions to have practical impact when combined with other intervention types. It seems implicitly to assume that for each type of behavior there is a single, universal best estimate of the amount of change that can be achieved by each type of intervention. For interactions of intervention types, it seems to presume that there is a single best estimate of each interaction effect that could be made by analyzing appropriately collected data. The evidence from multiple research methods indicates otherwise $\mathrm{e}^{2,4,9-11}$. It indicates that the effects of behavioral interventions depend on multiple contextual factors, which may be physical, institutional, economic, cognitive, attitudinal, etc., and which can create barriers to change. It shows that the greatest behavioral plasticity is achieved by intervention packages that adequately address the specific barriers to change that apply to target behaviors, populations, and contexts. In short, behavioral interventions can have their greatest impact when other interventions reduce non-behavioral barriers. For example, behavioral response to identical financial incentives for home weatherization has varied tenfold due to non-technical and non-economic factors in implementation ${ }^{12}$.

Multi-method research has generated design principles for practical interventions that integrate behavioral and other intervention types, particularly for high-impact actions, and that can be adapted to a variety of contexts ${ }^{2,4,13,14}$. The principles emphasize the needs for marketing to get households to consider taking high-impact actions, providing valid information from credible sources at points of decision, making information about choices simple, and providing credible quality assurance for household investments in low-emissions technologies ${ }^{4,7,13}$. Behavior- and context-specific interventions may seem less attractive than economy-wide interventions such as carbon taxes and markets, but because limiting climate change is an urgent priority and because these approaches face major challenges of adoption and implementation ${ }^{15}$, focusing on high-impact behaviors is important now and will remain so as economy-wide interventions are developed.

The idea that responsiveness to behavioral interventions is context specific, and not a constant, is not readily tested by controlled experimentation, but it has robust support. Additionally, it suggests a fundamental limitation of treating controlled experimentation as the gold-standard methodology in this domain. What can be learned from randomized controlled trials can be valuable, but its limitations for drawing broad conclusions for policy need to be taken seriously.

Analysis of the findings of ref. ${ }^{1}$ reveals the limits of generalizing from single variable analyses of behavioral interventions, focusing on frequently repeated actions, and seeking universal, context-independent, generalizations about the effects of particular intervention strategies on particular types of behavior. As other research strongly indicates, well targeted behavioral interventions, particularly focused on infrequent, higher-impact actions, can have significant impact when non-behavioral barriers are reduced. Useful practical advice can come from research focused on high-impact actions, using multiple research methods, considering contextual effects, and examining promising combinations of behavioral and other intervention types, to address and overcome barriers to change for specific behaviors in specific contexts $^{3,4,7}$.

\section{Data availabilty}

Data sharing not applicable.

Received: 26 October 2019; Accepted: 23 January 2020;

Published online: 14 February 2020

\section{References}

1. Nisa, C. F., Bélanger, J. J., Schumpe, B. M. \& Faller, D. G. Meta-analysis of randomised controlled trials testing behavioural interventions to promote household action on climate change. Nat. Commun. 10, 4545 (2019).

2. Gardner, G. T. \& Stern, P. C. Environmental Problems and Human Behavior 2nd edn. (Pearson Custom Publishing, 2002).

3. Dietz, T., Gardner, G. T., Gilligan, J., Stern, P. C. \& Vandenbergh, M. P. Household actions can provide a behavioral wedge to rapidly reduce U.S. carbon emissions. Proc. Natl Acad. Sci. USA 106, 18452-18456 (2009).

4. Wolske, K. S. \& Stern, P. C. in Psychology and Climate Change: Human Perceptions, Impacts, and Responses. (eds Clayton, S. \& Manning, C.) 127-160 (Elsevier, 2018)

5. Black, J. S., Stern, P. C. \& Elworth, J. T. Personal and contextual influences on household energy adaptations. J. Appl. Psychol. 70, 3-21 (1985).

6. Stern, P. C. \& Gardner, G. T. Psychological research and energy policy. Am. Psychol. 36, 329-342 (1980).

7. Kastner, I. \& Stern, P. C. Examining the decision-making processes behind household energy investments: A review. Energy Res. Soc. Sci. 10, 72-89 (2015).

8. Stern, P. C. et al. Opportunities and insights for reducing fossil fuel consumption by households and organizations. Nat. Energy, 1, 16043 (2016).

9. Šćepanovića, S., Warnier, M. \& Nurminena, J. K. The role of context in residential energy interventions: a meta review. Renew. Sustain. Energy Rev. 77, 1146-1168 (2017).

10. Osbaldiston, R. \& Schott, J. P. Environmental sustainability and behavioral science: meta-analysis of pro-environmental behavior experiments. Environ. Behav. 44, 257-299 (2012).

11. de la Rue du Can, S., Leventis, G., Phadke, A. \& Gopal, A. Design of incentive programs for accelerating penetration of energy-efficient appliances. Energy Policy 72, 56-66 (2014)

12. Stern, P. C. et al. The effectiveness of incentives for residential energy conservation. Eval. Rev. 10, 147-176 (1986).

13. Stern, P. C., Gardner, G. T., Vandenbergh, M. P., Dietz, T. \& Gilligan, J. Design principles for carbon emissions reduction programs. Environ. Sci. Techn. 44, 4847-4848 (2010).

14. Stern, P. C., Wittenberg, I., Wolske, K. S. \& Kastner, I. Cambridge Handbook of Psychology and Economic Behaviour 2nd edn. (ed Lewis, A.) 541-566. (Cambridge University Press, Cambridge, 2018).

15. Vandenbergh, M. P. \& Gilligan, J. Beyond Politics: The Private Governance Response to Climate Change (Cambridge University Press, Cambridge, 2017).

\section{Author contributions}

P.C.S. was the sole contributor.

\section{Competing interests}

The authors declare no competing interests.

\section{Additional information}

Correspondence and requests for materials should be addressed to P.C.S.

Peer review information Nature Communications thanks PeiYi (Patricia) Kuo for their contribution to the peer review of this work.

Reprints and permission information is available at http://www.nature.com/reprints

Publisher's note Springer Nature remains neutral with regard to jurisdictional claims in published maps and institutional affiliations. 
(c) (i) Open Access This article is licensed under a Creative Commons Attribution 4.0 International License, which permits use, sharing, adaptation, distribution and reproduction in any medium or format, as long as you give appropriate credit to the original author(s) and the source, provide a link to the Creative Commons license, and indicate if changes were made. The images or other third party material in this article are included in the article's Creative Commons license, unless indicated otherwise in a credit line to the material. If material is not included in the article's Creative Commons license and your intended use is not permitted by statutory regulation or exceeds the permitted use, you will need to obtain permission directly from the copyright holder. To view a copy of this license, visit http://creativecommons.org/ licenses/by/4.0/.

(C) The Author(s) 2020 